\title{
University Student Shopping Patterns: Internet vs. Brick And Mortar
}

\author{
Emilija Arnaudovska, Southeastern Louisiana University, USA \\ Kelly Bankston, Southeastern Louisiana University, USA \\ Jana Simurkova, Southeastern Louisiana University, USA \\ Michael C. Budden, Southeastern Louisiana University, USA
}

\begin{abstract}
In today's retail environment there are some who enjoy shopping and some who do not. People have many options when it comes to where they shop; they can shop from home or venture out to the store. Shopping has never been as fast and convenient as it is today. Technology is more advanced and internet usage is rapidly increasing. Retailers are realizing internet shopping is a phenomenon that is not going to disappear. It is a rare retailer who has no web presence. In order to satisfy customers, managers need to examine how people shop. College students have their own shopping behavior as this study examines.
\end{abstract}

Keywords: Shopping, student behavior, online shopping, retailing

\section{INTRODUCTION}

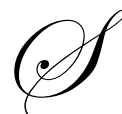

hopping is a multifaceted experience. Sometimes, it is conducted for the purpose of acquiring goods and services that are deemed to be needed by consumers. Other times, the driving force behind shopping is not necessarily the acquisition of goods and services so much as it is a manner for individuals to seek and acquire social relationships and the benefits of related social interactions. Solomon (p. 373; 2009) points out that consumers shop for both utilitarian reasons and hedonic reasons.

Court (2006) discusses the desire of consumers to have fun and be entertained while shopping. However, what is considered fun by one person may be considered agony to another. While some shop for fun or entertainment; there are some who shop not for enjoyment but out of other obligations. Indeed, Solomon (2009) proffers the driving forces behind shopping are many and complex. Solomon mentions that research on sex roles in shopping differ as women may find emotional fulfillment in the act of buying whereas men wish to demonstrate their expertise and shop to win. The social underpinnings of shopping are driving much research and taking such research into new areas. For instance, Underhill (2009) discusses the increasing role anthropologists are playing in the administration of shopper and consumer insight groups.

Regardless of whether or not someone enjoys shopping, regardless of motivation, and regardless of location or method, on some level everyone shops. Today's society is bombarded with new ways to shop. The internet has revolutionized retailing and created avenues to serve customers that heretofore have been impossible. Dunne and Lusch (p. 11; 2008) recognize that the changing face of retailing requires entrepreneurs capable of forging new approaches to serve emerging market opportunities. Indeed, they mention a study (p. 4) that concluded many CEOs lost their positions due to their inability to manage change.

When contemplating the world of shopping there are many areas to be examined. Shopping is a vast subject matter, which has been intently studied by people from many different walks of life with many different interests. In this research study, the scope was focused on the shopping behavior of college students. Specific variables including gender, mode of shopping and the willingness of shoppers to seek outside opinions were investigated. 


\section{METHODOLOGY}

A questionnaire was developed to gather the shopping habits of students. The survey consisted of questions directly related to shopping habits. The questions varied from simple "yes" or "no" responses to openended questions. A survey was administered to graduate and undergraduate students at a university in the southern U.S. A total of 144 usable questionnaires were collected in a convenience sample during a two week period in spring 2009. The written questions were answered anonymously.

\section{FINDINGS}

\section{Background Respondents}

Age ranges of the respondents varied with 17-21 year olds accounting for 37\%, 22 to 25 years old represented $48 \%$ of the sample, while the remaining $15 \%$ were 26 years of age and older. In respect to school classification, the following classifications were represented: freshman $12.5 \%$, sophomore $10.4 \%$, junior $20.1 \%$, senior $25.0 \%$, and Graduate $31.9 \%$. The sample was comprised of $39.6 \%$ male and $60.4 \%$ female. On the campus, female students represented about $2 / 3$ of all students, so the sample's gender breakdown was not too different from the population. The majority of respondents, $63.9 \%$, indicated their main source of income was earned by them.

\section{You Can Have Whatever You Like: Shopping Preferences}

Overall, respondents indicated they (78.5\%) like shopping. Unsurprisingly, females were more likely to enjoy shopping than men. As was mentioned earlier, women may be more emotionally attached to shopping and find more pleasure in it.

The findings indicated the older you get the less you enjoy shopping. Only $59.1 \%$ of respondents 26 years of age or older indicated they enjoyed shopping; $78.3 \%$ of respondents from the ages of 22 to 25 enjoyed shopping; while $86.5 \%$ of respondents from the ages of 17 to 21 enjoyed it. Also, $92 \%$ of respondents whose main source of income was reported as parents and/or relatives enjoyed shopping. Younger students may enjoy shopping more as they are spending funds that were given to them. Younger students were primarily female while the majority of male respondents were older.

Table 1

\begin{tabular}{|c|c|c|c|c|}
\hline & \multicolumn{2}{|c|}{ Age } & Total \\
\hline Do you like shopping? & $17-21$ & $22-25$ & $26+$ & All \\
\hline Yes & $46(86.8 \%)$ & $54(78.3 \%)$ & $13(59.1 \%)$ & 113 \\
\hline
\end{tabular}

\section{The Battle of the Sexes}

Shopping is often enjoyed by women who derive both physical and hedonic satisfaction from the experience. Ostensibly, men may shop with women for moral and financial support. This may indeed be a concept of a gender difference of sorts, but are these views of shopping accurate? Do men avoid shopping and must be brought kicking and screaming by their significant other to the experience or do they secretly enjoy shopping? Given the chance to avoid shopping, will men take it?

In this study, there were specific variables tested. Among the most interesting was a gender comparison with who liked to shop, which indicated a majority of both men and women enjoy shopping. However, $92 \%$ of women indicated they enjoy shopping while only $58 \%$ of men reported doing so. It is not surprising that a greater percentage of women reported enjoying shopping than men. What was surprising to the researchers is that a majority of male respondents indicated they enjoyed shopping. 


\section{Online vs. Stores}

The general population today is indeed bombarded with technology; a vast amount of which has been embraced by today's youth. The majority of the population cannot get through the day without some sort of technological interaction. Since today's college students were raised in a technological age, "it is no surprise that internet usage among college respondents has seen a marked increase in recent years" (Budden et al, 2007). "Internet usage among U.S. adults has risen and is reportedly at $56 \%$ for predominantly white, well-educated and affluent individuals" (Odell et al, 2000). Also, Ott (2005) reported approximately 30\% of "panelists" reported making an online purchase within a 30 day period. Williams, Waterwall and Giardelli (2008) discuss the widespread availability of credit cards to college students. Williams, et al found that the majority of students they studied used credit cards for emergencies, gasoline and groceries - not for internet purchases. Thus, the ability of college students to shop on the internet is significant.

In this study, respondents were asked to indicate whether they were more likely to make clothing purchases online or in a store. Pearse (2009) reported that over two-thirds of consumers believed online shopping to be both cheaper and offer better value than a brick and mortar store. Still, in this study, $80.6 \%$ of respondents were likely to make clothing purchases in-store. This makes sense to some degree given the nature of clothing and fit; however, (Ott, 2005) found that only $51 \%$ of panelists strongly agreed with the statement "I prefer to purchase inside the store, rather than online or by catalog". Most respondents who like shopping are likely to make in-store clothing purchases.

Male respondents were more likely to shop for clothing online than women. A higher percentage of male students, $24.6 \%$, reported purchasing most of their clothing online while only $16.1 \%$ of female students reported purchasing clothing online.

\section{Frequency of Shopping}

The majority of the population enjoys shopping. And women enjoy it more than men. Pope (2007) found that most people find shopping to be fun and exciting and that they enjoy seeing new products in stores. Two-thirds of respondents $(66.7 \%)$ indicated they are most likely to go shopping 1-3 times a month, whether online or in a store. A large proportion of respondents (45.8\%) were likely to go shopping 1-3 times per month online.

\section{To Ask or Not to Ask: Shopping Companions and Opinions}

The research indicated $66 \%$ of respondents like to shop with a shopping companion. Chart 1 indicates with whom respondents normally shop. Moreover, out of 144 respondents, 101 respondents indicated that they like someone else's opinion while they are shopping for clothing. "When two women shop together, they talk, advise, suggest and consult to their heart's content, hence the long time in the store, with the kids, she's partly consumed with herding them along and keeping them entertained: alone, she makes efficient use of her time" (Underhill, 1999).

Table 2: Preferred Shopping Companions

\begin{tabular}{|c|c|c|c|c|}
\hline Friend & Relative & Significant Other & Alone & Total \\
\hline 47 & 26 & 22 & 49 & 144 \\
\hline $32.60 \%$ & $18.10 \%$ & $15.30 \%$ & $34 \%$ & $100 \%$ \\
\hline
\end{tabular}

As seen in Table 2, 49 respondents reported they usually shop alone. Out of the 144 total, 47 specified they normally shop with a friend, 26 shop with a relative, while 22 shop with a significant other. Further analysis of data for differences in shopping preferences among respondents, who were accompanied by different people or shopping alone, was conducted. The research concluded of 144 respondents, 113 like shopping and 31 do not like shopping at all. 
As seen in Table 3, the percentage of respondents who reported liking shopping is 79\% (113 of 144 respondents). In addition, 35\% of respondents who shop alone do not like shopping. Table 3 displays how respondents' preference for shopping is influenced by whether or not they shop with a companion.

Table 3: Shopping Companions and their Influence on Shopping Preferences

\begin{tabular}{|c|c|c|c|c|c|c|}
\hline & & Friend & Relative & Significant Other & Alone & Total \\
\hline $\begin{array}{c}\text { Do you like } \\
\text { shopping? }\end{array}$ & Yes & 42 & 23 & 16 & 32 & $113(79 \%)$ \\
& & $(89 \%)$ & $(88 \%)$ & $(73 \%)$ & $(65 \%)$ & \\
\hline & No & 5 & 3 & 6 & 17 & $31(22 \%)$ \\
$(11 \%)$ & $(12 \%)$ & $27 \%)$ & $(35 \%)$ & \\
\hline Total & & 47 & 26 & 22 & 49 & 144 \\
\hline
\end{tabular}

Results were not surprising. There is a high correlation between the accompanying shopping companion and from whom respondents seek advice while shopping for clothing. For example, if a student shops alone they are not likely to seek anyone else's opinion of their clothing choices. The research found $65 \%$ of respondents who reported shopping alone do not seek anyone else's opinion; however, $10 \%$ of them will consider a salesperson's opinion. Not surprisingly, $79 \%$ of respondents, who shop with friends, seek their friend's opinion relative to clothing purchases.

\section{Pick Your Poison: Clothing and Who Buys Them}

Respondents were found to purchase different clothing articles from stores than from online retailers. Court (2006) finds that today's consumers are savvy and use a combination of shopping channels to meet their needs. Only $19.4 \%$ of respondents report purchasing clothing off of the internet. Court mentions that a key question relates to whether online purchases are replacing an in-store purchase or whether the purchase is one that might not have been made given a lack of internet access. When respondents were asked what clothing article they are most likely to purchase online $33.3 \%$ of the 144 respondents responded they are most likely to purchase a shirt/blouse. In addition, only $6.9 \%$ responded they are most likely to buy pants and/or skirt from the internet. However, when purchasing clothing articles in a store, most of the respondents, 35.4\%, are most likely to purchase pants and/or skirts. These findings seem to lead to the conclusion that some purchases made online do not replace purchases made in-stores. Even though the internet is a very powerful tool the observed occurrence of the respondents that do not shop online was surprisingly high. Of 144 respondents, $27.1 \%$ responded they do not shop online. Table 4 reports the number/percentage of respondents indicating the source of clothing purchases.

Table 4

\begin{tabular}{|c|c|c|c|c|}
\hline & Shirt/Blouse & Pants/Skirt & Shoes & Underwear/Lingerie \\
\hline Internet & $15(55.5 \%)$ & $5(18.5 \%)$ & $5(18.5 \%)$ & $2(7.4 \%)$ \\
\hline Store & $43(37.0 \%)$ & $35(30.1 \%)$ & $30(25.8 \%)$ & $8(6.89 \%)$ \\
\hline
\end{tabular}

Table 4 displays the relationship between the numbers of respondents who make their clothing purchases online and the clothing article they are likely to purchase through the internet. As was mentioned earlier, 27 respondents (19.4\%) make their clothing purchase online. Of those 27 respondents, 55.5\% are likely to purchase a shirt and/or blouse; $18.5 \%$ are likely to purchase pants; another $18.5 \%$ are likely to purchase shoes; while only $7.4 \%$ are likely to purchase underwear and/or lingerie.

The relationship between the number of respondents who are likely to make their clothing purchase in a store and the article of clothing they are most likely to buy can also be seen in Table 4. Of the 144 respondents responding, 116 have a preference to purchase clothing articles in a store. Table 4 indicates that $37.0 \%$ are likely to purchase a shirt and/or blouse in a store. The collected research indicates that students are likely to purchase a shirt and/or blouse from the store and the internet. Table 4 also indicates $30.1 \%$ of respondents who purchase pants and/or skirts are more likely to purchase them in a store; while the number of individuals who purchase shoes from a store do so at a rate six times higher than those who do so online. 


\section{Online vs. Store: Semantic Differential}

A comparison was made to evaluate the preferences of online shopping versus store shopping. Due to the increasing popularity of online shopping, the findings are interesting. The results for the semantic differential comparison are displayed in the graph below. Ratings on the scale above 3.0 indicate negative traits and numbers under 3.0 indicate positive traits: The lower the rating number, the more positive the perceived value of the variable. A rating of 3.0 would be a neutral rating. As shown, the data implies respondents generally think more favorably of online shopping than in-store shopping. There is a significant difference in opinion when it comes to the speed of shopping. Respondents consider online shopping quicker than store shopping. Online shopping is considered more convenient, user-friendly, cheaper, and easier than in-store shopping. All opinions of stores lean more toward neutral (3.0) than do opinions of online shopping. Respondents indicated an overall preference for online shopping - though most shopping is done in brick and mortar stores.

\section{Store vs Internet}

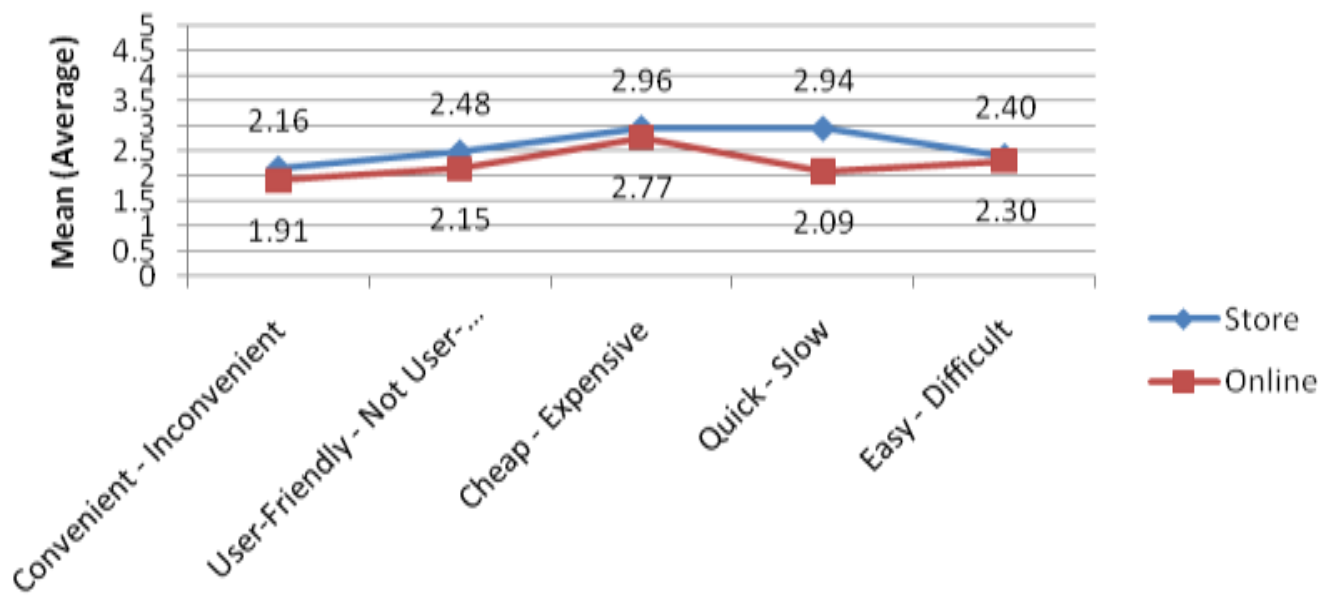

Variables

\section{Limitations}

Generalizations of these findings should be approached with caution. The sample was a convenience sample administered in the form of an anonymous survey to students at one university in the Southeast U.S. It is recommended that additional study be conducted of a larger and more representative college student sample, to shed further light on the shopping behavior of college students.

\section{CONCLUSION}

The research conducted found most college students surveyed enjoy shopping. In the study, female respondents indicated they enjoy shopping at a greater percentage than do males. The research suggests the most popular item for purchase both in-stores and online was a shirt or blouse. For their shopping experience, most respondents like to have a shopping companion, who according to the majority of respondents was a family member. Respondents also indicated they desire someone else's opinion (most of the time provided by their shopping companion) on their clothing selections. Students who do not like to shop usually shop by themselves and may seek the opinion of sales clerks relative to their purchase intentions.

Even though today's economy is not booming, respondents indicated they enjoy shopping and continue to patronize stores. The internet is indeed becoming increasingly popular, and respondents indicated they are more 
likely to shop in-stores as opposed to on the internet. However, respondents do consider online shopping to be more convenient, user-friendly, cheaper, quicker, and easier. It remains to be seen whether or not online shopping will overcome store shopping altogether, but due to the responses in the current study this seems unlikely especially as regards shopping for clothing. Maybe future generations will continue to embrace the internet and online shopping or maybe they will follow past generations and continue to patronize "brick and mortar" stores. Due to shopping being a source of entertainment for many individuals, the traditional store will likely never be obsolete, but may diminish in number as internet retailers continue to increase their market presence and share.

\section{AUTHOR INFORMATION}

Emilija Arnaudovska, received her MBA from Southeastern Louisiana University. She is preparing to enter a doctoral degree program in marketing. Her research interests include consumer behavior, ethics and management decision making.

Kelly Bankston is pursuing an MBA degree at Southeastern Louisiana University. Her research interests include law, ethics and business education.

Jana Simurkova is pursuing a MBA from Southeastern Louisiana University. Her research interests include consumer behavior, sports marketing and social marketing.

Michael C. Budden, is the Mayfield Professor of Marketing at Southeastern Louisiana University. His research interests include consumer behavior, retailing and commercial law.

\section{REFERENCES}

1. Budden, C. B., Anthony, J. F., Budden, C. M., \& Jones, A. M. (2007). Managing the Evolution of a Revolution: Marketing Implications of Internet Media Usage Among College Students. College Teaching Methods \& Styles Journal , 3, 5-10.

2. Court, Y. (2006, November 11). Getting shoppers out of the mouse. Estates Gazette. p52-54.

3. Dunne, P. M. and Lusch, R. F. (2008). Retailing, $6^{\text {th }}$. Thomson / South-Western, Mason, OH.

4. Odell, P., Korgan, K., Schumachere, P., \& Delucchi, M. (2000). Internet Use Among Female and Male College Students. Cyber Psychology \& Behavior, 3 (5), 855-862.

5. Ott, B. (2005, December 20). Is There a Digital Divide in Online Shopping? Retrieved March 7, 2009, from Gallup: http://www.gallup.com/poll/20527/There-Digital-Divide-Online-Shopping.aspx

6. Pearse, J. (2009, January 8). Value Brands Need to Follow the Purse Holders Online. New Media Age , 2.

7. Solomon, M. R. (2009). Consumer Behavior: Buying, Having and Being, $8^{\text {th }}$. Pearson Prentice-Hall, Upper Saddle River, NJ.

8. Underhill, P. (2009). Why We Buy: The Science of Shopping (updated and revised): Simon \& Schuster Paperbacks, NY, NY.

9. Underhill, P. (1999). Why We Buy: The Science of Shopping: Simon \& Schuster Paperbacks, NY, NY. 10. Williams, D., Waterwall, B. and Giardelli, T. (2008, $4^{\text {th }}$ Quarter). An investigation into Credit Card Debt Among College Students. Contemporary Issues in Education Research, Vol. 1, Number 4, 43-50. 